
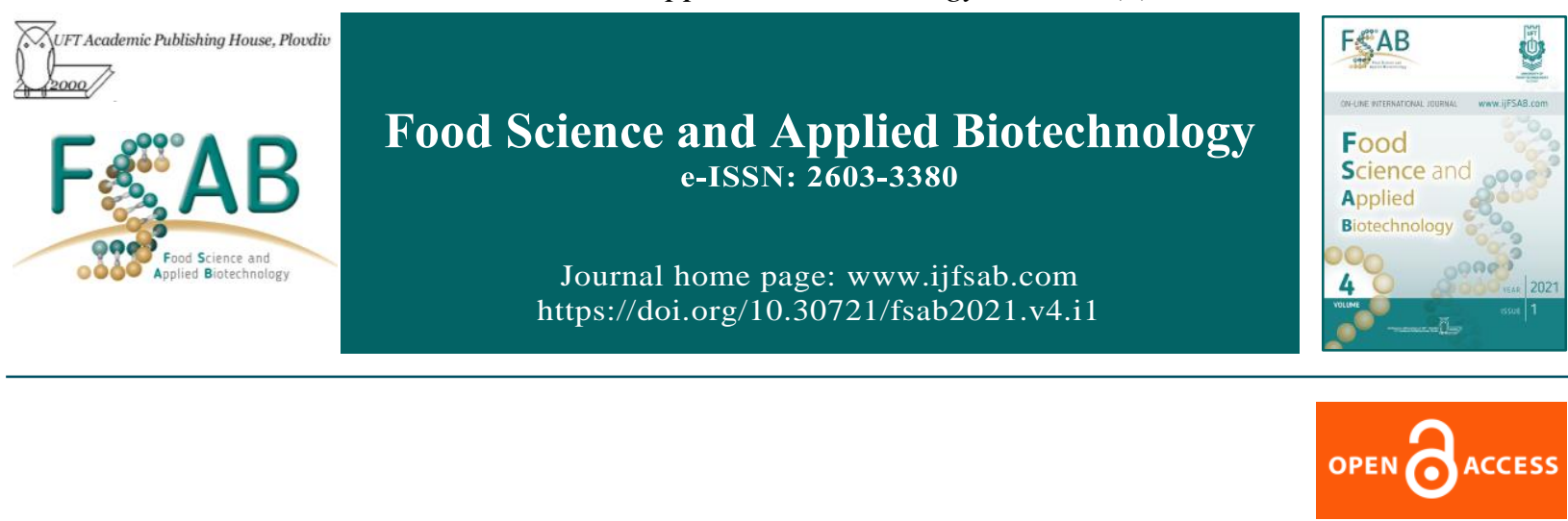

Research Article

\title{
Study of the biological activity of essential oils-water mixtures
}

Nevena Lazarova-Zdravkova ${ }^{1 \boxminus}$, Denitsa Tsanova ${ }^{1}$, Yoana Stoyanova $^{1}$, Chavdar Chilev $^{2}$, Nelly Georgieva $^{1}$, Dimitar Peshev ${ }^{2}$

${ }^{1}$ Department of Biotechnology, Faculty of Chemical and System Engineering, UCTM, Sofia, Bulgaria

${ }^{2}$ Department of Chemical Engineering, UCTM, Sofia, Bulgaria

\begin{abstract}
This study aimed to investigate the biological activity of aqueous mixtures of two essential oils. The mixtures were prepared by mixing certain amounts of lavender and clove oils with distilled water at room temperature. In the case of lavender oil, a relatively clear saturated aqueous phase was obtained after mixing with an excess of the essential oil. The clove oil formed stable oil-in-water emulsions. The antibacterial activity of the samples was tested against two model bacterial strains. The growth of the Gram-negative Escherichia coli K12 and the Gram-positive Bacillus subtilis 3562 was determined in 96-well microplates. A more prominent inhibition activity against $E$. coli K12 strain compared to B. subtilis 3562 for both oilwater mixtures was observed. A disk diffusion test indicated growth inhibition by the lavender oil during the tests against the Gram-positive strain (zones of around $11.7 \mathrm{~mm}$ ) while clove oil inhibited both bacteria (12 mm - B. subtilis 3562 and $13.66 \mathrm{~mm}$ - E. coli K12). The DPPH free radical method showed no antioxidant activity for the aqueous solution of lavender oil. The pure lavender oil exhibited negligible activity compared to the gallic acid reference solution, the clove essential oil, and its emulsion. A quantitative relationship between the content of cloves essential oil in the emulsion and its radical scavenging capacity was demonstrated.
\end{abstract}

Keywords: essential oils, antioxidant activity, antibacterial activity

Abbreviations: 2,2-diphenyl-1-picrylhydrazyl (DPPH)

${ }^{\square}$ Corresponding author: N. Lazarova-Zdravkova, Department of Biotechnology, Faculty of Chemical and System Engineering, University of Chemical Technology and Metallurgy, bul. Kliment Ohridski 8, Sofia, Bulgaria, tel.: ++359886008 312; E-mail: nevena@uctm.edu

\footnotetext{
Article history:

Received 22 November 2020

Reviewed 21 February 2021

Accepted 05 March 2021

Available on-line 19 March 2021
}

https://doi.org/10.30721/fsab2021.v4.i1.130

(C) 2021 The Authors. UFT Academic publishing house, Plovdiv 


\section{Introduction}

There is evidence that essential oils are part of human life for over 5.000 years (Fischer-Rizzi 1990). At the same time synthetic medications, cosmetics and food preservatives are relatively new for mankind, and in the last few decades, there are many concerns about their adverse effects on both human health and nature (Kalemba and Kunicka 2003). A natural and fast-growing alternative with expected global market demand of around 470 kilotons by 2027 (Grand View Research, Inc. 2020) is the aromatic plants and related products with their well-known biological activity. There are more than 40 known species of Lavandula (common name lavender). In recent years Bulgaria has overtaken France to become the world leader in lavender oil production with approximately 51681 tons of lavender fresh flowers produced during 2019. The most widely cultivated among them is Lavandula angustifolia formerly L. officinalis. The scent of lavender is used for cosmetics, fragrances, and even honey (Ministry of Agriculture Food and Forestry 2020; Stanev et al. 2016). Products derived from the Lavender plant (Lavandula spp.) have been used for centuries as a therapeutic agent and in particular, its essential oil was widely used as an antibacterial agent in World War I (Cavanagh et al. 2005). The oil is also believed to have sedative, anti-depressive, carminative and anti-inflammatory properties which, however, is not verified by the scientific community. Lavender essential oil is primarily composed of monoterpenoids and sesquiterpenoids with major representatives linalool and linalyl acetate which are proven strong antimicrobial agents against foodborne bacteria (Hossain et al. 2017). The essential oil isolated from the buds of Eugenia caryophyllata L. Merr. \& Perry (Myrtaceae) also found in the literature as Syzygium aromaticum is widely used and well known for its medicinal properties. It is grown naturally in Moluccas Islands, East Indonesia, and was cultivated in Tanzania, Madagascar, Sri Langka, India, Malaysia, Brazil, Jamaica, and Guinea (Sohilait 2015). The major component of the flower buds (cloves) oil is usually considered to be eugenol, with lesser and variable amounts of $\beta$ caryophyllene and other components such as benzyl alcohol (Chaieb et al. 2007). The antimicrobial activity of eugenol is associated with its ability to permeabilize the cell membrane and interact with proteins. The hydroxyl group of eugenol is thought to bind to and affect the properties of the proteins (Hyldgaard et al. 2012). Clove oil is widely used in aromatherapy and flavouring. Additionally, it has a variety of other benefits ranging from antiinflammatory for oral infections to curing toothaches and acne. Due to its wide application in the pharmaceutical, fragrance, and food industries, the demand for clove oil is expected to rise to six thousand tons by 2022 (SpendEdge 2018). At the same time to produce a single pound of essential oil, vast amounts of plants are required (Schieber et al. 2005; Gavarić et al. 2015). This means that the steam distillation of the plants to produce essential oils generates large amounts of waste materials including aqueous fractions with certain amounts of the oils in them. Depending on the concentration of the main constituents and their biological activity, these effluents could have a negative impact on the environment.

The aim of this work was to evaluate and compare the antibacterial and antioxidant activity of the lavender and cloves essential oil-water mixtures mimicking the essential oil industry effluents. This will allow for the prediction of the biological activity of the industrial waste hydrosols or aqueous extracts and the possibilities for their valorization. The pure oils have also been analysed and their activity compared with that of the aqueous mixtures to obtain a better understanding of the correlation between the concentration of oils in the aqueous mixtures and their biological activities.

\section{Materials and Methods}

Liquid and solid (agar) medium, Luria Bertani (LB) for $E$. coli $\mathrm{K} 12$, and Nutrient Broth (NB) for $B$. subtilis 3562, both from HiMedia Laboratories were prepared for the bacteria. The strains were obtained from the Bulgarian National Bank of Industrial Microorganisms and Cell Culture and conserved in our laboratory. The cultures were incubated in Shaker ES-20/60. Sterile filter paper discs $(6 \mathrm{~mm}$ in diameter) by HiMedia Laboratories were used for the antibacterial experiments. Commercially available essential oils from lavender (Lavandula angustifolia, Bioherba ${ }^{\mathrm{R}}$ ) and cloves (Eugenia caryophyllata, Eterika) were used. The aqueous mixtures from the two oils were prepared by mixing 
certain amounts of lavender and clove oils with distilled water at room temperature. For the sample preparation, a separatory funnel of $1 \mathrm{~L}$ volume was used. In the case of lavender oil, a relatively clear saturated aqueous phase was obtained after mixing with an excess of the essential oil with a final concentration of $0.55 \mathrm{mg} / \mathrm{ml}$. A stable cloves oil-inwater emulsion with a concentration of $3.49 \mathrm{mg} / \mathrm{ml}$ was prepared and used in this work. In both cases the aqueous fraction was obtained following a single procedure including vigorous mixing of an exact volume of water with an excess of oil, settling the emulsion for 5 days at room temperature (20$25^{\circ} \mathrm{C}$ ) and separating the oil fraction.

\section{Methods}

Antibacterial experiments. The antibacterial activity of the lavender and clove samples was tested against facultative anaerobic Gram-negative E. coli $\mathrm{K} 12$ and aerobic Gram-positive B. subtilis 3562 by using the agar disk diffusion test and a broth microdilution method. The cultures were grown, sub-cultured, and maintained in LB and NB solid medium and stored in the fridge at $4^{\circ} \mathrm{C}$. For the experiments, a single colony of the organisms was inoculated into $50 \mathrm{ml} \mathrm{LB}$ and $\mathrm{NB}$ broth and incubated overnight $\left(24 \mathrm{~h}\right.$ ) at $37^{\circ} \mathrm{C}$ and $30^{\circ} \mathrm{C}$ for $E$. coli $\mathrm{K} 12$ and $B$. subtilis 3562 respectively with shaking at $220 \mathrm{rpm} .100 \mu \mathrm{l}$ of bacterial suspensions with a concentration of $0.5 \mathrm{McF}$ arland (comparable to a bacterial suspension of $1.5 \times 10^{8} \mathrm{CFU} / \mathrm{ml}$ ) were seeded on agar plates with solid medium- LB or NB respectively by the pour plate technique. Sterile paper discs were impregnated with $6 \mu$ of the pure essential oils and their oil-water mixtures $(0.55$ $\mathrm{mg} / \mathrm{ml}$ lavender aqueous solution and $3.49 \mathrm{mg} / \mathrm{ml}$ cloves essential oil emulsion), and placed on the surface of the agar plate. A disc with the same amount of distilled water was used as a control. The formation of a clear zone (restricted bacterial growth) is an indication of antibacterial activity for the studied materials. Inhibition zones were measured edge to edge across the zone of inhibition over the center of the disk according to the KirbyBauer Disk Diffusion Susceptibility Test Protocol after incubation overnight at the preferred temperature for each strain (Hudzicki 2009). Mean values of the inhibition zones were determined by performing the experiments in triplicate as described previously (Georgieva et al. 2015). For the broth microdilution method, 96-well microplates were used and analysed by a Microplate Reader PKL PPC 142 (Paramedical, Italy). The method is used to measure the in vitro activity of an antimicrobial agent against bacterial cells. By a turbidity detector DEN-1B (Biosan, Latvia) the bacterial inoculum was again set to $0.5 \mathrm{McFarland}$. A volume of $60 \mu \mathrm{l}$ cell culture was added to $120 \mu \mathrm{l}$ of broth media. During these experiments the medium was prepared with the aqueous solution of lavender and the cloves oil emulsion respectively, giving the possibility to further dilute the tested agents. Control samples were prepared in standard NB and LB media respectively. The concentrations of all samples analysed are presented in Table 1. The bacterial growth was detected at a wavelength of $630 \mathrm{~nm}$ at the beginning of the experiment, at the $6^{\text {th }}$, and at the $24^{\text {th }}$ hour of cultivation. All samples were performed in five replicates and mean values were used to calculate the percent reduction in the growth of both strains in the presence of the oilswater mixtures.

Antioxidant capacity determination. The $\mathrm{DPPH}^{\circ}$ (2,2-diphenyl-1-picrylhydrazyl) radical scavenging assay has been commonly used for the determination of the antioxidant activity of different essential oils (Jirovetz et al. 2006; Wang et al. 2008; Kivrak 2018). The antioxidant compounds reduce the $\mathrm{DPPH}^{\circ}$ radical to $\mathrm{DPPH}-\mathrm{H}$ decreasing its spectrophotometric absorbance. The assay for analysing the samples was previously described (Peshev et al. 2011). Pure essential oils were diluted with ethanol $96 \% \mathrm{v} / \mathrm{v}$; the aqueous solutions and oil in water emulsions were diluted with distilled water. Each sample contained $1.5 \mathrm{~mL}$ of the $\mathrm{DPPH}^{\circ}$ solution and $0.05 \mathrm{~mL}$ of the investigated antioxidant. In one of them, no antioxidant was added and it was used as a blank assay. Gallic acid was used as a reference solution with a concentration of $0.01 \mathrm{mg} / \mathrm{ml}$. Samples were mixed and kept in a dark place. Their absorbance was measured periodically using a T70 UV/Vis Spectrometer (PG Instruments Ltd) at $\lambda=517 \mathrm{~nm}$. The free radical scavenging activity of each sample was then evaluated as percent quenched or remnant $\mathrm{DPPH}^{*}$ defined as:

$$
\% \text { quenched } \mathrm{DPPH} \bullet=\frac{100(\mathrm{Ab}-\mathrm{As})}{\mathrm{Ab}}
$$


\% remnant $\mathrm{DPPH} \bullet=100-\%$ quenched $\mathrm{DPPH} \bullet(2)$

where $A_{s}$ and $A_{b}$ are the absorbances of the analysed and blank sample, respectively. The antioxidant power was also characterized by the $\mathrm{EC}_{50}$ value (the concentration necessary to reduce $50 \%$ of the initial $\mathrm{DPPH}^{*}$ present in the sample). The samples of the investigated antioxidant products were analysed in triplicate.

Table 1. Concentration of the essential oil-water samples used in the broth microdilution method

Sample type and concentration

\begin{tabular}{lc}
\hline Lavender oil aqueous solution mg (lavender oil aqueous solution)/ & $0.37 ; 0.28 ; 0.25$ \\
ml (sample) & $2.33 ; 1.94 ; 1.56 ;$ \\
Cloves oil emulsion mg (cloves oil emulsion)/ & $0.37 ; 0.28 ; 0.25$ \\
ml (sample) & \\
\hline
\end{tabular}

\section{Results and Discussion}

The first part of the experiments was performed with the lavender samples. With the broth dilution method, no activity of the lavender oil aqueous solution was detected against $B$. subtilis 3562 (Table 2). Reductions of around 32, 25 and $25 \%$ were measured for the growth of E. coli $\mathrm{K} 12$ at the $24^{\text {th }}$ hour for the concentrations of $0.37 \mathrm{mg}$ (lavender oil aqueous solution) $/ \mathrm{ml}$ (sample), $0.28 \mathrm{mg}$ (lavender oil aqueous solution)/ml(sample) and $0.25 \mathrm{mg}$ (lavender oil aqueous solution)/ml(sample), respectively. Since the lavender volatile organic compounds mainly contribute to its antimicrobial activity, the negligible antimicrobial activity of hydrosols seems reasonable due to their low content of volatile components (Prusinowska et al. 2016). This hypothesis has been also confirmed by the study of Moon et al. (2006) where no antibacterial activity was observed with either the hydrosols or the aqueous extract of $L$. angustifolia. The microdilution method applied to the cloves oil emulsion samples (Table 2) showed that in its higher concentrations $(2.33 \mathrm{mg}$ (cloves oil emulsion)/ml(sample), $1.94 \mathrm{mg}$ (cloves oil emulsion)/ml(sample) and $1.56 \mathrm{mg}$ (cloves oil emulsion)/ml(sample)) the inhibition of the growth of both - E. coli $\mathrm{K} 12$ and B. subtilis 3562 is significant. The concentration of $2.33 \mathrm{mg}$ (cloves oil emulsion)/ml(sample) inhibited the growth of the two strains at more than $90 \%$ percent (minimal inhibitory concentration - $\mathrm{MIC}_{90}$ ). We have also observed that the cloves oil emulsion in its concentrations below $1.56 \mathrm{mg}$ (cloves oil emulsion)/ml(sample) inhibited the growth of both strains stronger in the first hours. The measurement at the $24^{\text {th }}$ hour suggested that both bacteria have partially adapted to the inhibitor. The lower the concentration of the cloves oil emulsion, the lower was the percent measured reduction against $B$. subtilis at the $24^{\text {th }}$ hour. Hussien et al. (2011), have also concluded that several aromatic spice and herb hydrosols, including cloves, have antibacterial effects against several Gram-positive and negative bacteria. In line with our findings, Hyldgaard et al. (2012), have reported that the main component in the clove oil (eugenol) in concentrations in the range from 0.8 to $3 \mathrm{mg} / \mathrm{ml}$ inhibits different strains of the E. coli bacteria. Most studies regarding the mechanism of antimicrobial action of essential oils and their constituents have shown that Gramnegative bacteria are generally less susceptible than Gram-positive bacteria (Trombetta et al. 2005; Hyldgaard et al. 2012). This is due to the outer membrane of Gram-negative bacteria (containing hydrophilic lipopolysaccharides) which creates a barrier toward macromolecules and hydrophobic compounds like those in essential oils (Nikaido 2003).

In contrast, our observations showed that eugenol has higher antimicrobial activity against Gramnegative bacteria than Gram-positive bacteria. Hyldgaard et al. (2015), have also reported the same phenomenon for eugenol. They have also observed stronger activity against yeasts and molds compared to Gram-positive bacteria and further supported the findings of other researchers that the antimicrobial activity of essential oils differ because of their 
complex nature while their content varies depending on the season of harvest, the methods used for their extraction and at the same time the mechanisms of action against different bacterial strains are quite specific (Espina et al. 2011; Demuner et al. 2011; Paibon et al. 2011).

Table 2. Microdilution test results

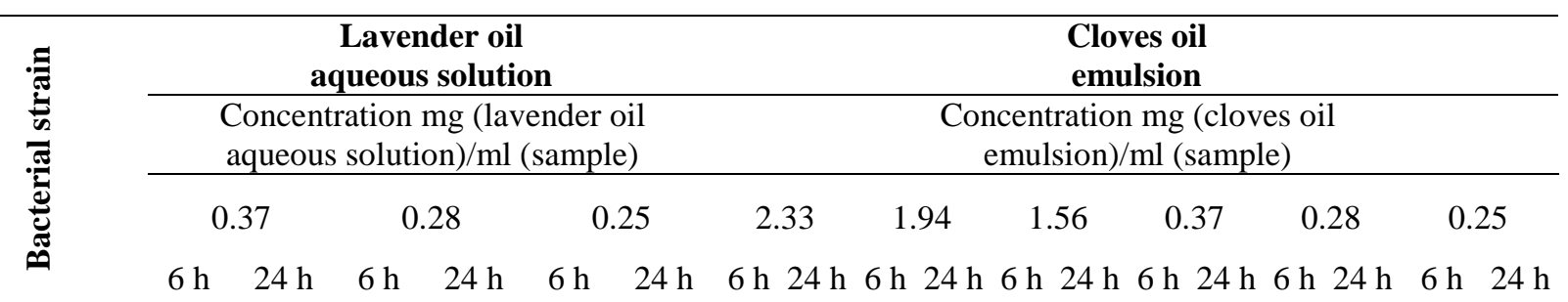

Growth reduction, \%

\begin{tabular}{|c|c|c|c|c|c|c|c|c|c|c|c|c|c|c|c|c|c|c|}
\hline $\begin{array}{l}\text { B. subtilis } \\
3562\end{array}$ & 0 & 0 & 0 & 0 & 0 & 0 & 96 & 96 & 78 & 49 & 42 & 40 & 30 & 27 & 30 & 11 & 28 & 7 \\
\hline $\begin{array}{c}\text { E. coli } \\
\text { K } 12\end{array}$ & 0 & 32 & 0 & 25 & 0 & 25 & 98 & 94 & 97 & 81 & 78 & 76 & 29 & 0 & 25 & 0 & 11 & 0 \\
\hline
\end{tabular}

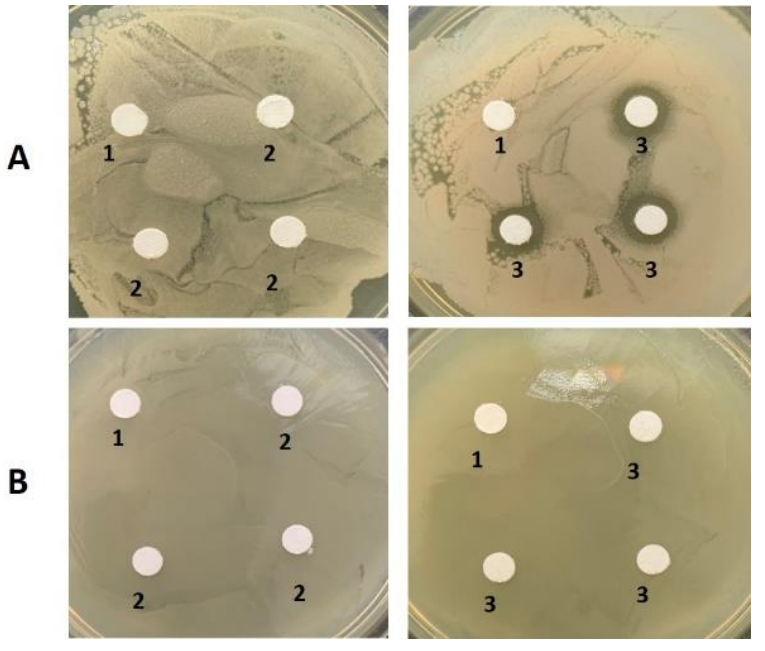

Figure 1. Antibacterial test results of lavender samples against B. subtilis 3562 (row A) and E. coli $\mathrm{K} 12$ (row B) - control (1), lavender aqueous solution (2), lavender essential oil (3)

According to Hayes et al. (1997), E. coli is also more susceptible to tea tree oil compared to the Gram-positive Staphylococcus aureus. Hili et al. (1997) reported the same trend for many other essential oils. The aqueous solutions of lavender oil were also tested using the agar diffusion test. No inhibition zones were observed (Fig. 1). With this method we also evaluated the pure lavender essential oil. No inhibition was observed against the
E. coli $\mathrm{K} 12$ strain (Fig. 1B) but zones of around 11.7 $\mathrm{mm}$ were determined in the petri dishes inoculated with B. subtilis 3562 (Fig. 1A). The cloves essential oil led to the appearance of inhibition zones for both bacteria - $12 \mathrm{~mm}$ (B. subtilis 3562 ) and $13.66 \mathrm{~mm}$ (E. coli K12) (Fig. 2). Hosseini et al. (2019), reported similar observations.

A
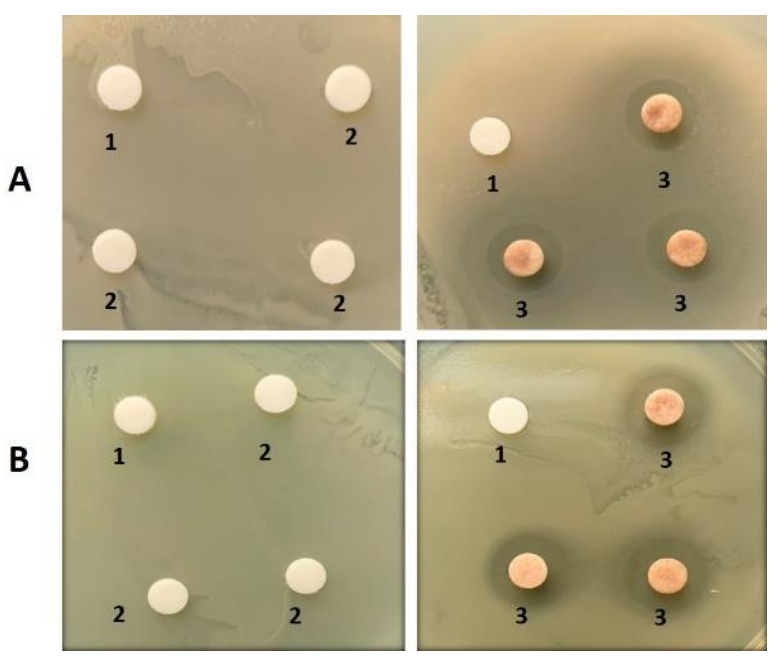

Figure 2. Antibacterial test results of clove samples against $B$. subtilis 3562 (row A) and $E$. coli $\mathrm{K} 12$ (row B) - control (1), cloves oil emulsion (2), cloves essential oil (3) 
They have observed inhibition zones of approximately $12.05 \mathrm{~mm}$ for E. coli PTCC 1399 and slightly larger zones for the Gram-positive Bacillus cereus PTCC $1154(13.25 \mathrm{~mm})$. As in the case of lavender aqueous solutions, no inhibition was observed for the cloves oil emulsion and its dilutions.

The samples of lavender and clove were also analysed by the DPPH assay. It can be seen that cloves essential oil and emulsion react rapidly with DPPH$^{*}$ in less than 30 min (Fig. 3).
The gallic acid used as a reference antioxidant compound also reacts up to the $30^{\text {th }} \mathrm{min}$ and reaches a steady state after that. Therefore, the samples were allowed to react for a standard time of $60 \mathrm{~min}$ in all further measurements.

Lavender essential oil and its aqueous solutions did not show significant inhibition activity. Jirovetz et al. (2006), have also reported significant inhibitory activity for cloves oil in comparison to eugenol, butylated hydroxytoluene (BHT), and butylated hydroxyanisole (BHA).

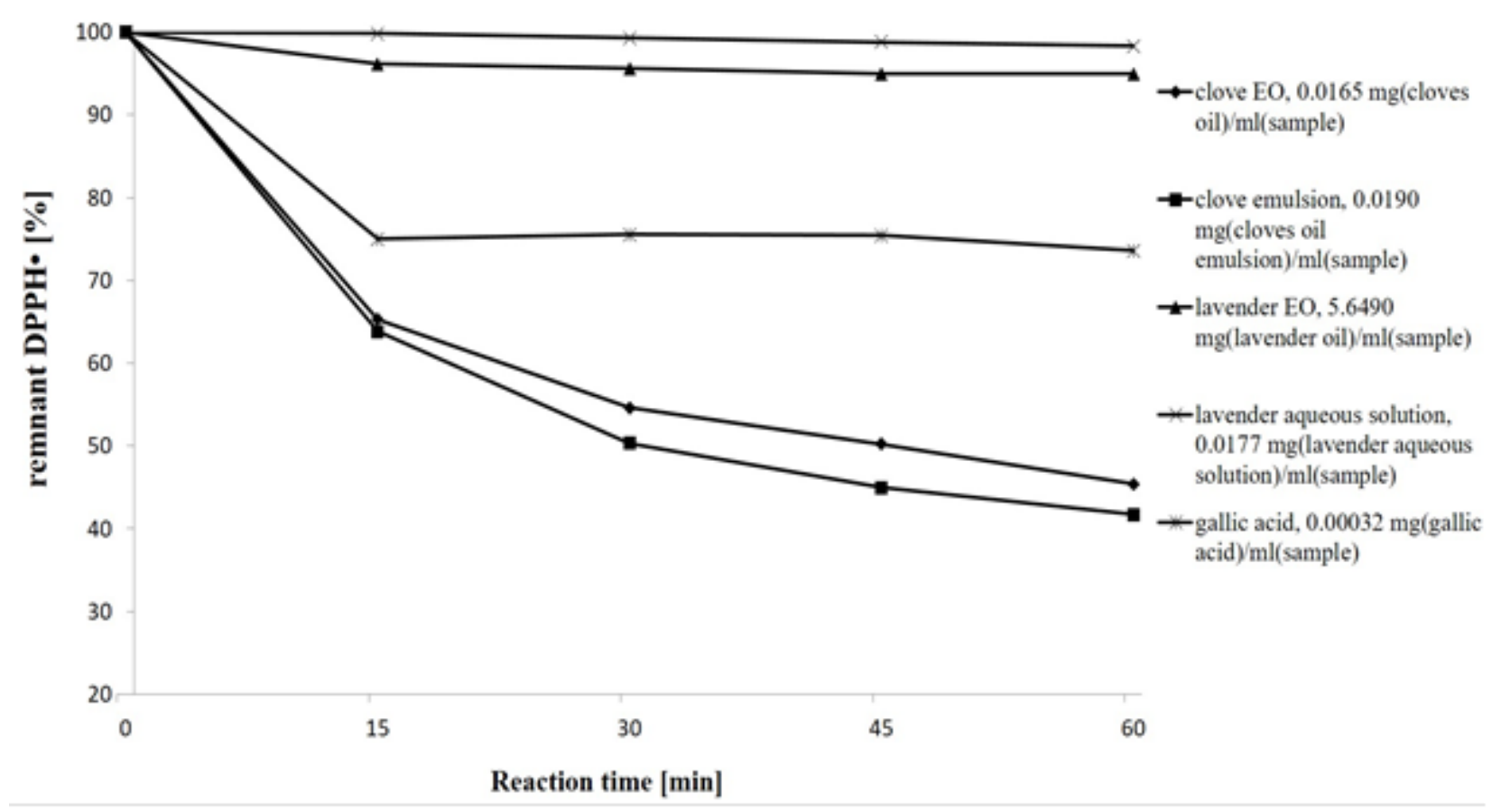

Figure 3. Kinetics of the characteristic radical scavenging reaction of lavender and cloves essential oil (EO), lavender aqueous solution, cloves oil emulsion and gallic acid with DPPH 
The obtained $\mathrm{EC}_{50}$ values for the cloves oil and its aqueous emulsion measured at a reaction time of 60 min for each sample (Fig. 4) proved the possibility of using the radical scavenging activity as a practical tool for quantitative evaluation of the concentration of cloves essential oil in its aqueous emulsions. Indeed, the cloves oil emulsion was 286 times diluted oil in water while the ratio of the $\mathrm{EC}_{50}$ values of the emulsion and the pure essential oil was 296 , indicating that dilution of the cloves essential oil in water to form emulsion does not alter its radical scavenging activity determined following the described protocol.

\section{Conclusions}

The present investigation has shown that the cloves essential oil and its oil-in-water emulsion have relatively higher biological activity compared to lavender essential oil and its aqueous solution.

The microdilution assay indicated more prominent inhibition activity against $E$. coli $\mathrm{K} 12$ strain in comparison to B. subtilis 3562 for both oil-water mixtures. The results from the disk diffusion test confirmed the growth inhibition of both strains and greater in the case of the E. coli K12 with cloves oil while lavender oil inhibited only the Gram-positive strain. Significant antioxidant activity was observed for the cloves essential oil and its emulsion. Moreover, a quantitative relationship between the content of cloves essential oil in the emulsion and its radical scavenging capacity was demonstrated, allowing to use the DPPH • antioxidant assay as a practical tool for quantitative analysis of industrially obtained distillates or aqueous extracts during steam or hydrodistillation of cloves. All of our findings suggest that the aqueous by-products obtained during the cloves essential oil production are good candidates for future applications as preservatives in the cosmetics, food and pharma industry. However, detailed characterization of the chemical composition for all of the samples will give us a better understanding of the intensity and mechanisms of biological activities.

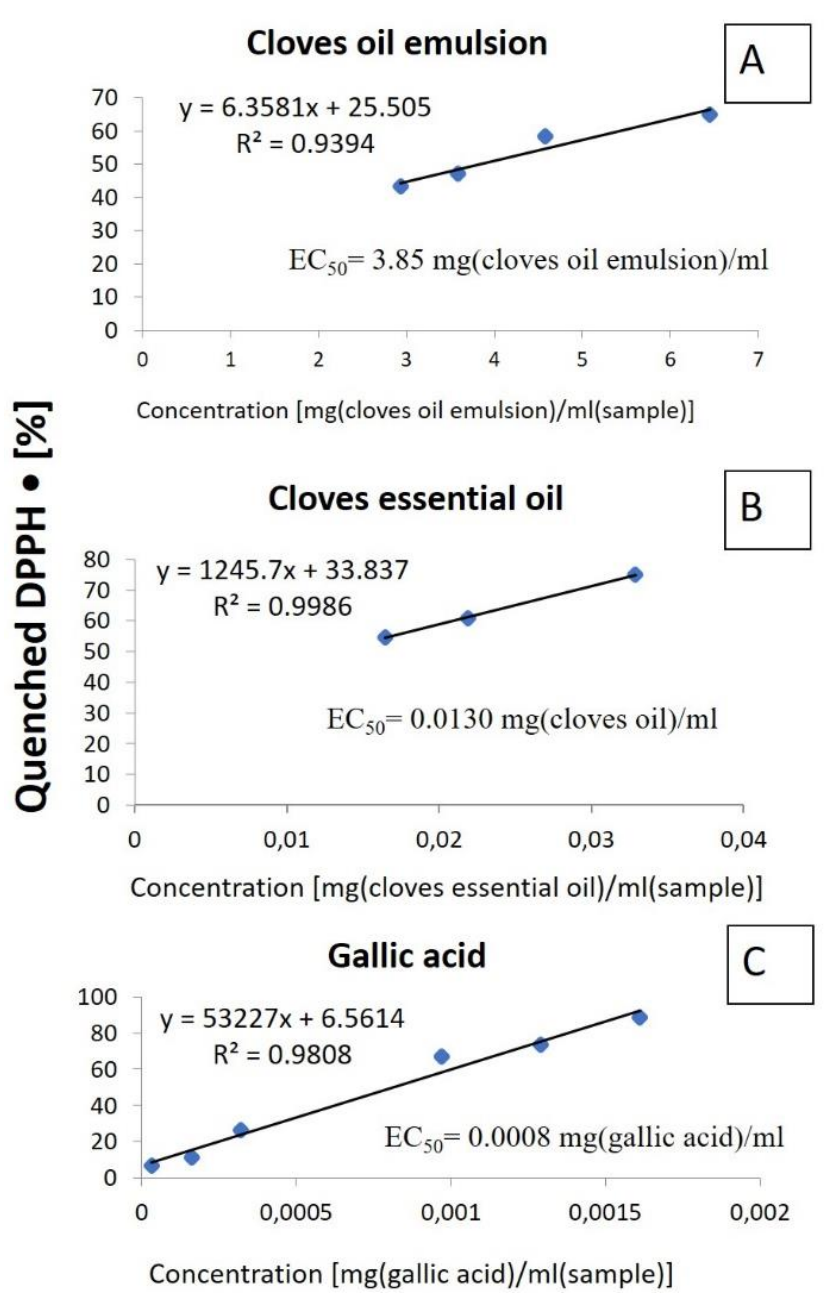

Figure 4. Experimental data and curve fitting for $\mathrm{DPPH}^{*}$ quenching for $60 \mathrm{~min}$ by cloves oil emulsion (A), cloves essential oil (B), and gallic acid $(C)$ versus concentration of antioxidant in the samples

\section{Acknowledgements}

This work was supported by the Bulgarian National Science Fund (contract KP-06-H37/14).

\section{References}

Cavanagh H.M.A., Wilkinson J.M. Lavender essential oil: a review. Australian Infection Control, 2005, 10(1): 35-37. https://doi.org/10.1071/HI05035

Chaieb K., Hajlaoui H., Zmantar T., Kahla- Nakbi A.B., Rouabhia M., Mahdouani K., Bakhrouf, A. The chemical composition and biological activity of clove essential oil, Eugenia caryophyllata (Syzigium aromaticum L. Myrtaceae): a short review. Phytotherapy Research: An International Journal Devoted to Pharmacological and 
Toxicological Evaluation of Natural Product Derivatives, 2007, 21(6): 501-506. https://doi.org/10.1002/ptr.2124

Demuner A.J., Almeida Barbosa L.C., Gonçalves Magalhaes C., Da Silva C.J., Alvares Maltha C. R., Lelis Pinheiro A. Seasonal variation in the chemical composition and antimicrobial activity of volatile oils of three species of Leptospermum (Myrtaceae) grown in Brazil. Molecules, 2011, 16(2): 1181-1191. https://doi.org/10.3390/molecules 16021181

Espina L., Somolinos M., Lorán S., Conchello P., García D., Pagán R. Chemical composition of commercial citrus fruit essential oils and evaluation of their antimicrobial activity acting alone or in combined processes. Food Control, 2011, 22(6): 896-902. https://doi.org/10.1016/j.foodcont.2010.11.021

Fischer-Rizzi S. Complete aromatherapy handbook: Essential oils for radiant health. Sterling Publishing Company, Inc., New York, 1990, 240 pages. Print ISBN-10: 0806982225 ; Print ISBN-13: 978-0806982229

Gavarić N., Kladar N., Mišan A., Nikolić A., Samojlik I., Mimica-Dukić N., Božin B. Postdistillation waste material of thyme (Thymus vulgaris L., Lamiaceae) as a potential source of biologically active compounds. Industrial Crops and Products, 2015, 74(11): 457-464. https://doi.org/10.1016/j.indcrop.2015.05.070

Georgieva N., Angelova Ts., Juarez A.G.V., Müller R. Antifungal activity of $\mathrm{SiO}_{2}$ /cellulose hybrid materials doped with silver nanoparticles against Candida albicans 74. Comptes rendus de l'Acad'emie bulgare des Sciences, 2015, 68(10): 1259-1264. Available at: http://www.proceedings.bas.bg/

Grand View Research, Inc. Essential Oils Market Growth \& Trends, 2020. Available at:

https://www.grandviewresearch.com/press-release/globalessential-oil-market

Hayes A.J., Leac, D.N., Markham J.L., Markovic B. In vitro cytotoxicity of Australian tea tree oil using human cell lines. Journal of Essential Oil Research, 1997, 9(5): 575582. https://doi.org/10.1080/10412905.1997.9700780

Hili P., Evans C.S., Veness R.G. Antimicrobial action of essential oils: the effect of dimethylsulphoxide on the activity of cinnamon oil. Letters in Applied Microbiology, 1997, 24(4): 269-275. https://doi.org/10.1046/j.1472765X.1997.00073.x

Hyldgaard M., Mygind T., Louise Meyer R. Essential oils in food preservation: mode of action, synergies, and interactions with food matrix components. Frontiers in Microbiology, 2012, 3(1): 12. https://doi.org/10.3389/fmicb.2012.00012

Hyldgaard M., Mygind T., Piotrowska R., Foss M., Louise Meyer R. Isoeugenol has a non-disruptive detergent-like mechanism of action. Frontiers in Microbiology, 2015, 6(7): 754. https://doi.org/10.3389/fmicb.2015.00754

Hossain S., Heo H., De Silva B.C.J., Wimalasena S.H.M.P., Pathirana H.N.K.S., Heo G.J. Antibacterial activity of essential oil from lavender (Lavandula angustifolia) against pet turtle-borne pathogenic bacteria. Laboratory Animal Research, 2017, 33(3): 195-201. https://doi.org/10.5625/lar.2017.33.3.195

Hosseini M., Jamshidi A., Raeisi M., Azizzadeh M. The Antibacterial and antioxidant effects of clove (Syzygium aromaticum) and lemon verbena (Aloysia citriodora) essential oils. Journal of Human, Environment and Health Promotion, 2019, 5(2): 86-93. http://doi.org/10.29252/jhehp.5.2.7

Hudzicki J. Kirby-Bauer disk diffusion susceptibility test protocol, 2009. Available from: https://asm.org/getattachment/2594ce26-bd44-47f6-82870657aa9185ad/Kirby-Bauer-Disk-Diffusion-

Susceptibility-Test-Protocol-pdf.pdf

Hussien J., Teshale C., Mohammed J. Assessment of the antimicrobial effects of some Ethiopian aromatic spice and herb hydrosols. International Journal of Pharmacology, 2011, 7(5): 635-640. http://doi.org/10.3923/ijp.2011.635.640

Jirovetz L., Buchbauer G., Stoilova I., Stoyanova A., Krastanov A., Schmidt E. Chemical composition and antioxidant properties of clove leaf essential oil. Journal of Agricultural and Food Chemistry, 2006, 54(17): 63036307. https://doi.org/10.1021/jf060608c

Kalemba D.A.A.K., Kunicka A. Antibacterial and antifungal properties of essential oils. Current Medicinal Chemistry, 2003, 10(10): 813-829. https://doi.org/10.2174/0929867033457719

Kıvrak, Ş. Essential oil composition and antioxidant activities of eight cultivars of Lavender and Lavandin from western Anatolia. Industrial Crops and Products, 2018, 117(7): 88-96. https://doi.org/10.1016/j.indcrop.2018.02.089

Marín I., Sayas-Barberá E., Viuda-Martos M., Navarro C., Sendra E. Chemical composition, antioxidant and antimicrobial activity of essential oils from organic fennel, parsley, and lavender from Spain. Foods, 2016, 5(1): 18. https://doi.org/10.3390/foods5010018

Ministry of Agriculture Food and Forestry. Crop yields harvest 2019 (Preliminary data) [Online]. Available at: https://www.mzh.government.bg/media/filer public/2020/ 03/31/ra369-preliminarypublicationcrops2019publ.pdf, March 2020, accessed 19.08.2020.

Moon T., Wilkinson J.M., Cavanagh H.M.A. Antibacterial activity of essential oils, hydrosols and plant extracts from Australian grown Lavandula spp. International Journal of Aromatherapy, 2006, 16(1): 9-14. https://doi.org/10.1016/j.ijat.2006.01.007

Nikaido H. Molecular basis of bacterial outer membrane permeability revisited. Microbiology and Molecular Biology Reviews, 2003, 67(4): 593-656. https://doi.org/10.1128/mmbr.67.4.593-656.2003

Paibon W., Yimnoi C. A., Tembab N., Boonlue W., Jampachaisri K., Nuengchamnong N., Ingkaninan K. Comparison and evaluation of volatile oils from three different extraction methods for some Thai fragrant flowers. International Journal of Cosmetic Science, 2011, 33(2): 150-156. https://doi.org/10.1111/j.14682494.2010.00603.x

Peshev D., Peeva L.G., Peev G., Baptista I.I.R. Application of organic solvent nanofiltration for concentration of antioxidant extracts of rosemary (Rosmarinus officiallis L.). Chemical Engineering Research and Design, 2011, 89(3): 318-327. https://doi.org/10.1016/J.CHERD.2010.07.002

Prusinowska R., Śmigielski K., Stobiecka A., KunickaStyczyńska A. Hydrolates from lavender (Lavandula 
angustifolia) - their chemical composition as well as aromatic, antimicrobial and antioxidant properties. Natural Product Research, 2016, 30(4): 386-393. http://doi.org/10.1080/14786419.2015.1016939

Schieber A., Mihalev K., Berardini N., Mollov P., Carle R. Flavonol glycosides from distilled petals of Rosa damascena Mill. Zeitschrift für Naturforschung C, 2005, 60(5-6): 379-384. https://doi.org/10.1515/znc-2005-5-602

Sohilait H. J. Chemical composition of the essential oils in Eugenia caryophylata, Thunb from Amboina Island. Science Journal of Chemistry, 2015, 3(6): 95-99. https://doi.org/10.11648/j.sjc.20150306.13

SpendEdge. What's Happening in the Global Clove Oil Market? 2018. Available at: https://www.spendedge.com/blogs/trends-global-clove-oilmarket

Spiridon I., Colceru S., Anghel N., Teaca C. A., Bodirlau R., Armatu A. Antioxidant capacity and total phenolic contents of oregano (Origanum vulgare), lavender (Lavandula angustifolia) and lemon balm (Melissa officinalis) from Romania. Natural Product Research, 2011, 25(17): 1657-1661. https://doi.org/10.1080/14786419.2010.521502

Stanev S., Zagorcheva T., Atanassov I. Lavender cultivation in Bulgaria - 21st century developments, breeding challenges and opportunities. Bulgarian Journal of Agricultural Science, 2016, 22(4): 584-590. Available at: http://agrojournal.org/22/04-09.pdf

Trombetta D., Castelli F., Sarpietro M. G., Venuti V., Cristani M., Daniele C., Bisignano, G. Mechanisms of antibacterial action of three monoterpenes. Antimicrobial Agents and Chemotherapy, 2005, 49(6): 2474-2478. https://doi.org/10.1128\%2FAAC.49.6.2474-2478.2005

Wang H.F., Wang Y.K., Yih K.H. DPPH free-radical scavenging ability, total phenolic content, and chemical composition analysis of forty-five kinds of essential oils. Journal of Cosmetic Science, 2008, 59(6): 509-522. https://doi.org/10.1111/j.1468-2494.2009.00531 5.x 